\title{
Management of Patients With Aortic Stenosis Requiring Non-Cardiac Surgery
}

\author{
Yoshiyuki Tokuda, MD, PhD; Akihiko Usui, MD, PhD
}

I $\mathrm{n}$ this issue of the Journal, Taniguchi et al report that severe, untreated, symptomatic or asymptomatic aortic stenosis (AS) is likely to be associated with a higher risk of perioperative death following major non-cardiac surgery. ${ }^{1}$ In their study, $4.3 \%$ of patients with severe AS who did not undergo prior aortic valve replacement (AVR) died following elective non-cardiac surgery, whereas none of the patients who underwent AVR before non-cardiac surgery died. Of note, none of the severe AS patients died following low-risk non-cardiac surgery (i.e., superficial surgery), even without AVR. Their study exclusively included severe AS patients and did not include patients with mild or moderate AS. Despite the limitations of the

\section{Article p 1173}

retrospective study design without risk adjustment, the study provides a clear message to clinicians: patients with severe AS, even if asymptomatic, might benefit from prior aortic valve intervention (surgical AVR (SAVR) or transcatheter AVR (TAVR)) before undergoing major noncardiac surgery.

Generally, early valvular intervention is strongly recommended in symptomatic severe AS patients because of their dismal prognosis. Assessment of the severity of AS is essential for decision-making. In general, a valve area of

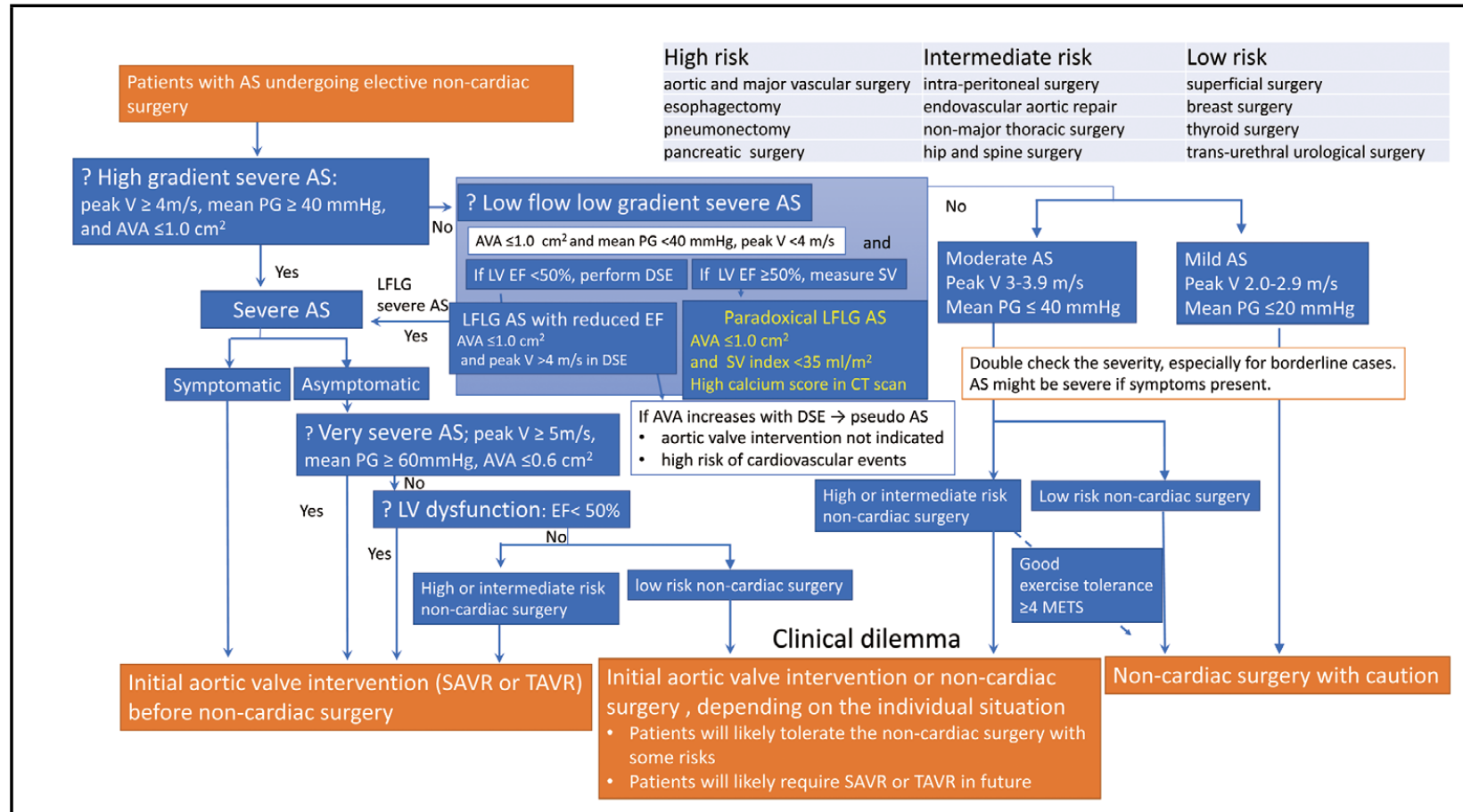

Figure. Management algorithm for patients with aortic stenosis (AS) requiring non-cardiac surgery. AVA, aortic valve area; DSE, dobutamine stress echocardiography; EF, ejection fraction; LFLG, low-flow low-gradient; LV, left ventricle; peak V, peak velocity (maximum velocity); PG, pressure gradient; SV, stroke volume.

The opinions expressed in this article are not necessarily those of the editors or of the Japanese Circulation Society.

Received May 1, 2020; accepted May 7, 2020; J-STAGE Advance Publication released online May 30, 2020

Department of Cardiac Surgery, Nagoya University Graduate School of Medicine, Nagoya, Japan

Mailing address: Yoshiyuki Tokuda, MD, PhD, Department of Cardiac Surgery, Nagoya University Graduate School of Medicine, 65 Tsurumai, Showa-ku, Nagoya 466-8550, Japan. E-mail: tokuda@mxb.mesh.ne.jp

ISSN-1346-9843 All rights are reserved to the Japanese Circulation Society. For permissions, please e-mail: cj@j-circ.or.jp 
$1.0 \mathrm{~cm}^{2}$ (or $0.6 \mathrm{~cm}^{2} / \mathrm{m}^{2}$ body surface area), a maximum velocity of $4 \mathrm{~m} / \mathrm{s}$, and a mean gradient of $40 \mathrm{mmHg}$ measured by echocardiography can be used as a definitive definition of severe AS in adults. ${ }^{2,3}$ It is increasingly recognized that a substantial number of patients classified as severe AS have lower pressure gradients, despite a stenotic aortic orifice. ${ }^{2,3}$ This entity is widely accepted as low-flow, low-gradient (LFLG) AS. LFLG AS is further subdivided into severe LFLG AS with reduced left ventricular ejection fraction ( $\mathrm{LVEF}<50 \%$ ), and severe LFLG AS with preserved LVEF (paradoxical LFLG severe AS), typically accompanied by concentric LV hypertrophy with a small ventricular cavity (stroke volume index $<35 \mathrm{~mL} / \mathrm{m}^{2}$ ). AVR is equally indicated for symptomatic LFLG severe AS patients.

If elective non-cardiac surgery is required in these symptomatic severe AS patients, SAVR or TAVR should be considered before the non-cardiac surgery, because such patients will anyway need to undergo SAVR or TAVR in the near future. Moreover, it has been reported that major non-cardiac surgery is associated with rapid progression of AS, probably because of activation of inflammation. ${ }^{4}$

In contrast to symptomatic patients, the indications for aortic valve intervention in asymptomatic patients with severe AS remain controversial. It is quite difficult to identify whether a patient with severe AS who declares no symptoms is truly asymptomatic. If hypotension or clinical symptoms are induced by exercise, such patients are regarded as symptomatic. ${ }^{3}$ Moreover, patients diagnosed with congestive heart failure should be regarded as "symptomatic. Additionally, aortic valve intervention is recommended for patients with very severe AS (maximum velocity $\geq 5.0 \mathrm{~m} / \mathrm{s}$, mean gradient $\geq 60 \mathrm{mmHg}$ ), even if asymptomatic. 2,5,6 Aortic valve intervention is similarly recommended if $\mathrm{LV}$ systolic dysfunction is present in asymptomatic severe AS patients. ${ }^{7}$ Thus, it is reasonable that these patients should undergo TAVR or SAVR before non-cardiac surgery (Figure).

The decision should also be based on the magnitude of the planned non-cardiac surgery., ${ }^{\mathbf{1 , 8}}$ Even if asymptomatic, for severe AS patients who require elective high-risk non-cardiac surgery (i.e., esophagectomy, major open vascular surgery), it might be reasonable to consider prior aortic valve intervention because of the proven increased risk of non-cardiac surgery. ${ }^{1}$ In contrast, asymptomatic mild to moderate AS patients with good exercise tolerance ( $\geq 4$ METS) can be expected to safely undergo low- or intermediate-risk non-cardiac surgery, if managed appropriately. ${ }^{5}$

Once it is determined that aortic valve intervention is necessary prior to non-cardiac surgery, the method of intervention (SAVR or TAVR) should be determined. The treatment choice depends on the duration for which the non-cardiac surgery can be delayed. For example, resection of malignancy cannot be delayed for long. In such cases, the fact that SAVR generally requires a longer recovery time than TAVR should be considered.

The current guideline includes a strong recommendation for TAVR in patients with symptomatic severe AS with a high or prohibitive risk for SAVR (STS score $>8 \%$ ). ${ }^{9}$ Additionally, recent trials showed similar or even better outcomes in low- to intermediate-risk patients (STS score 4-8\%) who underwent TAVR as compared with SAVR.10,11 Importantly, the procedural risk of TAVR depends greatly on the patient's anatomy. For example, the risk of coronary obstruction depends on coronary arterial height, size of the sinus of Valsalva (narrow root), and degree of calcification of the valve leaflets (presence of bulky cusps). The risk of annular rupture is related to subannular calcification. Moreover, procedural difficulty increases if there are access problems caused by a tortuous aorta or poor peripheral access. In cases with such TAVR-specific anatomic risks, SAVR becomes the preferred option. Of note, a nationwide study from Japan has shown that contemporary outcomes of SAVR continue to improve. ${ }^{12}$

Moreover, for porphyritic TAVR use in younger patients, it is important to ensure the durability of transcatheter aortic valves. To date, studies reporting on structural valve degeneration (SVD) up to 8 years after TAVR showed a very low rate of SVD, compared with that for SAVR. ${ }^{13}$ Although the midterm durability of transcatheter bioprosthesis is encouraging, the long-term durability remains largely unknown.

In conclusion, for patients with severe AS undergoing non-cardiac surgery, the indications for aortic valve intervention (TAVR or SAVR) should be assessed on multiple factors, including the severity of AS, magnitude of the non-cardiac surgery, symptoms and LV function. At the same time, the procedural risks and benefits of both SAVR and TAVR should be thoroughly evaluated.

\section{Disclosure}

A.U. is a member of Editorial Team (Associate Editor) of Circulation Journal.

\section{Conflict of Interest}

The authors declare no conflict of interest.

\section{References}

1. Taniguchi T, Morimoto T, Shiomi H, Ando K, Shirai S, Kanamori N, et al; on behalf of the CURRENT AS Registry Investigators. Elective non-cardiac surgery in patients with severe aortic stenosis: Observations from the CURRENT AS Registry. Circ J 2020; 84: 1173-1182.

2. Nishimura RA, Otto CM, Bonow RO, Carabello BA, Erwin JP 3rd, Guyton RA, et al. 2014 AHA/ACC Guideline for the management of patients with valvular heart disease: Executive summary: A report of the American College of Cardiology/ American Heart Association Task Force on Practice Guidelines. Circ J 2014; 129: 2440-2492.

3. Seo Y, Aonuma K. An ideal time to solve a clinical dilemma in the golden age of aortic stenosis therapy. Circ J 2016; 80: 1712 1714 .

4. Mizuno R, Yamagami ST, Higashi T, Nakada Y, Takeda Y, Okayama S, et al. Major non-cardiac surgery is a risk factor for rapid hemodynamic progression of non-rheumatic aortic stenosis. Circ J 2015; 79: 867-872.

5. Kristensen SD, Knuuti J, Saraste A, Anker S, Bøtker HE, Hert $\mathrm{SD}$, et al. 2014 ESC/ESA Guidelines on non-cardiac surgery: Cardiovascular assessment and management: The Joint Task Force on non-cardiac surgery: Cardiovascular assessment and management of the European Society of Cardiology (ESC) and the European Society of Anaesthesiology (ESA). Eur Heart $J$ 2014; 35: 2383-2431.

6. Kang DH, Park SJ, Lee SA, Lee S, Kim DH, Kim HK, et al. Early surgery or conservative care for asymptomatic aortic stenosis. N Engl J Med 2020; 382: 111-119.

7. Taniguchi T, Morimoto T, Shiomi H, Ando K, Kanamori N, Murata K, et al. Prognostic impact of left ventricular ejection fraction in patients with severe aortic stenosis. JACC Cardiovasc Interv 2018; 11: 145-157.

8. Glance LG, Lustik SJ, Hannan EL, Osler TM, Mukamel DB, Qian F, et al. The Surgical Mortality Probability Model: Derivation and validation of a simple risk prediction rule for non-cardiac surgery. Ann Surg 2012; 255: 696-702.

9. Nishimura RA, Otto CM, Bonow RO, Carabello BA, Erwin JP 
3rd, Fleisher LA, et al. 2017 AHA/ACC Focused Update of the 2014 AHA/ACC Guideline for the management of patients with valvular heart disease: A report of the American College of Cardiology/American Heart Association Task Force on Clinical Practice Guidelines. Circulation 2017; 135: e1159-e1195.

10. Mack MJ, Leon MB, Thourani VH, Makkar R, Kodali SK, Russo M, et al. Transcatheter aortic-valve replacement with a balloon-expandable valve in low-risk patients. $N$ Engl $J$ Med 2019; 380: 1695-1705.

11. Popma JJ, Deeb GM, Yakubov SJ, Mumtaz M, Gada H, O’Hair
$\mathrm{D}$, et al. Transcatheter aortic-valve replacement with a selfexpanding valve in low-risk patients. $N$ Engl J Med 2019; 380: $1706-1715$.

12. Tokuda Y, Yamamoto H, Miyata H, Usui A, Motomura N; Japan Cardiovascular Surgery Database Organization. Contemporary outcomes of surgical aortic valve replacement in Japan. Circ $J$ 2020; 84: 277-282.

13. Costa G, Criscione E, Todaro D, Tamburino C, Barbanti M. Long-term transcatheter aortic valve durability. Interv Cardiol 2019; 14: 62-69. 